\title{
A PROBLEMATIZAÇÃO DAS ATIVIDADES EXPERIMENTAIS NA EDUCAÇÃO SUPERIOR EM QUÍMICA: UMA PESQUISA COM PRODUÇÕES TEXTUAIS DOCENTES - PARTE II
}

\author{
Fábio Peres Gonçalves* \\ Departamento de Química, Centro de Ciências Físicas e Matemáticas, Universidade Federal de Santa Catarina, CP 476, 88040- \\ 970 Florianópolis - SC, Brasil

\section{Carlos Aberto Marques} \\ Departamento de Metodologia de Ensino, Centro de Ciências da Educação, Universidade Federal de Santa Catarina, CP 476, \\ 88040-970 Florianópolis - SC, Brasil
}

Recebido em 22/2/11; aceito em 18/9/11; publicado na web em 6/12/11

\begin{abstract}
PROBLEMATIZATION OF EXPERIMENTAL ACTIVITIES IN CHEMISTRY FURTHER EDUCATION: A STUDY OF TEACHING TEXTS - PART II. Through the analysis of articles with proposals for experimental activities and with current pedagogical, epistemological and environmental discussion on experimentation by Chemistry professors, this paper investigates ways of highlighting relevant methodological characteristics that can be incorporated in experiments. 102 articles from national periodicals were analysed, all of which suggested experiments for use in Chemistry higher education. Based on analysis of the suggestions for experiments it appears that of particular importance are: visions, such as those that explain a belief that experimentation incentivizes motivation and conceptual learning; awareness of observation influenced by empiricism; and "errors" of students, which enrich their knowledge.
\end{abstract}

Keywords: experimentation; higher education; Chemistry teaching.

\section{INTRODUÇÃO}

Há indicativos de que entre professores de Ciências Naturais predomina um discurso simplista acerca da experimentação caracterizado, por exemplo, pela presença de uma visão empirista-indutivista da Ciência. ${ }^{1}$ Aspecto que, por si só, alude à necessidade de discutir as contribuições dos processos de formação de professores no enfrentamento dessa problemática, não restrita aos docentes da educação básica, pois envolve igualmente os professores da educação superior.

No entanto, a pesquisa sobre experimentação no ensino de $\mathrm{Ci}$ ências parece estar mais centralizada na educação básica do que na educação superior, uma vez que a educação superior em Química não tem sido investigada com pujança no cenário nacional. ${ }^{2,3}$ No Brasil, a explicação para essa tendência pode estar relacionada com o fato de as atividades experimentais estarem praticamente ausentes no ensino fundamental e médio das escolas brasileiras e isso seria um problema a ser enfrentado, sobretudo, por meio de propostas catalisadoras de sua inserção em sala de aula. Em contrapartida, na educação superior, os experimentos estão muito presentes. Todavia, nem sempre os estudantes conseguem se apropriar dos conhecimentos desenvolvidos nos experimentos, ${ }^{4} \mathrm{e}$ isso contribui para tornar a experimentação uma área de investigação em ensino de Ciências. Em suma, a ausência da experimentação na educação básica e o modo como é promovida nos espaços educativos são aspectos a serem enfrentados pelos docentes e pela pesquisa em ensino de Ciências, pois a mínima aprendizagem decorrente das atividades experimentais na educação superior também precisa ser reconhecida como um problema.

Com base nisso, investigaram-se, por meio de artigos com propostas de experimentos para a educação superior em Química, discursos pedagógicos, epistemológicos e ambientais relativos à experimentação presentes entre professores de Química da educação superior, como um modo de apontar características importantes de serem incorporadas em experimentos. Pretende-se com isso contribuir

*e-mail: fabio_peres@qmc.ufsc.br na sinalização de possibilidades metodológicas para a abordagem das atividades experimentais na educação superior em Química. Os resultados apresentados aqui complementam aqueles recentemente publicados. ${ }^{5}$ A análise das propostas de experimento foi orientada por uma perspectiva progressista de educação, fundamentada especialmente em ideias de Paulo Freire e exploradas previamente, ${ }^{5}$ ressaltando que, em tal perspectiva, se sinaliza de forma positiva, dentre outros aspectos, a utilização de materiais e reagentes de baixo custo para a promoção de experimentos e o diálogo decorrente da sua realização, assim como a necessidade de dar um destino acertado aos resíduos, quando for caso, não prejudicial ao meio biótico e abiótico. Assim, busca-se não só a aprendizagem de conteúdos conceituais como também a aprendizagem de atitudes em um contexto que supera a pura disciplinaridade e, ao mesmo tempo, valoriza uma abordagem dialógica que se contrapõe a uma "educação bancária", na linguagem freireana.

\section{A PESQUISA}

Reproduz-se, em parte, a descrição dos caminhos metodológicos para o desenvolvimento de uma investigação anteriormente divulgada. ${ }^{5}$ Foram analisados 102 artigos, publicados entre 1980 e 2007, com propostas de experimentos da seção Educação da revista Química Nova. A grande maioria dos artigos estava escrita em português e uma parcela menor em espanhol e inglês. O objetivo da seção é divulgar artigos de pesquisa em ensino de Química e propostas educacionais em Química, inovadoras para a graduação e pós-graduação. Apesar do objetivo da seção Educação já caracterizar o nível para o qual as propostas de experimento publicadas se destinam e, por conseguinte, os artigos aqui analisados, há sugestões de atividades experimentais ao longo dos anos que poderiam igualmente ser exploradas, com "adaptações", caso necessário, na educação básica — aspecto ressaltado pelos próprios autores dos artigos como se identificará na análise apresentada. Antes da Química Nova na Escola — periódico igualmente editado pela Sociedade Brasileira de Química —, criada 
em 1995, a Química Nova talvez se constituísse como principal disseminador dos resultados das investigações em ensino de Química no âmbito nacional. A Química Nova, até 2002, havia publicado 173 artigos na área de ensino de Química. ${ }^{2}$ Portanto, a divulgação de artigos a respeito do ensino de Química, também relacionados com a educação básica, caracteriza-se como uma importante contribuição desse periódico como difusor da produção acadêmica brasileira em ensino de Química, em uma época em que a comunidade nacional de pesquisa nesta área era ainda embrionária. ${ }^{2}$

As publicações brasileiras têm origem expressiva nas instituições públicas de ensino, bastante variadas, e abrangem conteúdos das diversas áreas da Química. Entre os autores e coautores, estão doutores em Química com reconhecida experiência. Outra característica de parte dos artigos é a presença de pós-graduandos stricto sensu em Química como autores e coautores, apesar dessa informação não estar explícita nos artigos. O acesso ao website do Conselho Nacional de Desenvolvimento Científico e Tecnológico (CNPq) possibilita obter o "Currículo Lattes" dos autores, fornecendo as informações referentes à sua formação. Essa descrição da autoria sugere que as propostas de experimento são elaboradas, basicamente, por professores de Química da educação superior.

Entre 1980 e 1989 foram publicados na seção Educação 66 trabalhos. Nos dez anos seguintes, houve um aumento dessas publicações: 77 artigos. Isso mostra que a revista acompanhou, de certa forma, o crescimento da área de ensino de Química no país na década de $1990{ }^{2}$ O número de publicações continuou crescente na seção Educação, visto que entre 2000 e 2007 foram publicados 121 artigos, dos quais 61 são propostas de atividades experimentais. Logo, neste último período, foram publicadas mais sugestões de experimento do que nos 20 anos anteriores. O número expressivo de propostas de experimentos ao longo dos anos na Química Nova é um indicativo do interesse dos químicos - autores e leitores - por esse assunto. $\mathrm{O}$ fortalecimento recente da cultura do publish or perish na educação superior brasileira também pode ter colaborado para esse aumento de artigos.

Aspectos apontados previamente ${ }^{5}$ em relação ao conjunto das propostas de experimento permanecem válidos para a presente análise. Por exemplo, há artigos em que as sugestões de experimento estão fracamente associadas a reflexões educacionais fundamentadas na literatura em ensino de Ciências. Outras considerações igualmente já publicadas sintetizam e antecipam um panorama em torno dessas propostas de experimento, com discussões também acerca dos avanços que podem representar, em seu conjunto, parte das sugestões de experimento publicadas na Química Nova, como a atenção aos resíduos ao longo dos anos e a caracterização diferenciada de propostas metodológicas para experimentos quando comparadas àquelas que se disseminaram em conhecidos projetos de ensino de Ciências (por exemplo, Chemical Education Material Study - CHEMS e cursos Nuffield) publicados na segunda metade do século passado.

Um dos critérios adotados na escolha das propostas de experimentos divulgadas na Química Nova é a qualidade desse periódico, avaliada e atestada por órgãos como a CAPES (Coordenação de Aperfeiçoamento de Pessoal de Nível Superior). Tem indexação no SciELO, no Chemical Abstracts e no Institute for Scientific Information (ISI), o que contribui na sua visibilidade e acesso nacional e internacional e como fator para justificar a sua escolha. Outra característica importante do periódico é a sua expressiva circulação na comunidade de químicos, com a tiragem (na época do início da pesquisa) de cerca de 2.900 exemplares por edição. Outro fator é que a seção Educação difunde discursos de formadores de professores de Química e de químicos, enquanto proponentes de atividades experimentais, a respeito da experimentação no ensino de Química.

As propostas de experimento foram submetidas aos procedimentos da análise textual discursiva ${ }^{6}$ que se constitui nas seguintes etapas: unitarização, categorização e comunicação. Na primeira etapa ocorreu a fragmentação dos textos em unidades de significado exploradas no decorrer do texto analítico sem a finalidade de classificar o artigo, como um todo, em certa perspectiva teórica e metodológica, nem mesmo os seus autores. Como se mencionou previamente, a investigação buscou analisar os discursos pedagógicos, epistemológicos e ambientais relativos à experimentação presentes entre professores de Química da educação superior que orientam suas produções textuais em torno da experimentação. Ao longo do texto as unidades de significado são utilizadas como uma maneira de ilustrar o discurso em discussão e de validar as interpretações do investigador. Isso colabora para superar um relativismo para o qual qualquer interpretação do pesquisador seria válida. Posteriormente, as unidades de significado foram agrupadas de acordo com suas semelhanças semânticas, o que configurou a categorização. Cabe ressaltar que a categorização foi orientada principalmente pelos pressupostos da perspectiva progressista de educação já exposta. Uma das funções das categorias é possibilitar uma compreensão aprofundada dos textos analisados. ${ }^{6} \mathrm{Na}$ comunicação foram produzidos textos descritivos e interpretativos em cada uma das categorias, quais sejam: a experimentação entremeada por princípios ético-ambientais; experimentação: dos materiais alternativos à informática; experimentação problematizadora; a dimensão estética das atividades experimentais; conteúdos na experimentação; a relação entre teoria e experimentação; motivação: "objetivo da experimentação?"; o erro e suas implicações na experimentação. Apresentam-se aqui as quatro últimas categorias, sendo que as demais já foram divulgadas. ${ }^{5}$

$\mathrm{Na}$ análise textual discursiva, é relevante transcender a descrição em direção à interpretação - embora já esteja tácita na descrição. Investir na interpretação significa expressar uma compreensão mais aprofundada do "objeto" pesquisado, para além da apresentação dos fragmentos dos textos analisados. A ênfase interpretativa se relaciona ao exercício de uma interlocução teórica que ajuda a fundamentar os posicionamentos apresentados pelo pesquisador. Isso contribui no sentido de reforçar o argumento de que inexiste neutralidade teórica na investigação e contraria a ideia de que qualquer interpretação seja válida.

Assim como na publicação anterior, destaca-se que as análises expostas nas categorias não tiveram o objetivo de emitir juízo sobre os pareceres ou pareceristas, bem como sobre a própria revista. A análise apresentada também não se configurou em uma tentativa de propor uma metodologia única para as atividades experimentais, pelo contrário. Em certas ocasiões, numerais em sobrescrito presentes nas transcrições foram subtraídos para não haver confusão com os numerais utilizados ao longo do artigo para indicar as referências.

\section{CONTEÚDOS NA EXPERIMENTAÇÃO: DOS CONCEITOS ÀS ATITUDES}

Os conteúdos ensinados por meio das atividades experimentais propostas nos artigos foram agrupados, para fins analíticos, em conceituais, procedimentais e atitudinais. ${ }^{7}$ Em relação aos conteúdos conceituais, um aspecto apontado foi a sua introdução por meio de experimentos:

O experimento proposto permite introduzir conceitos relacionados à análise em fluxo e detecção por quimiluminescência [...]. Desta forma, é adequado para ser implementado nas disciplinas de análise instrumental, Físico-Química ou Bioquímica [...]. Além disso, é possível a discussão sobre aspectos instrumentais envolvidos em diferentes métodos ópticos de análise (espectrofotometria e fluorescência $)^{8}$ (p. 341). 
De acordo com os autores, o experimento é um modo de introduzir conceitos. $\mathrm{O}$ ensino conceitual por intermédio de atividades experimentais é uma crença antiga entre os professores e a literatura indica que tais atividades podem contribuir positivamente à aprendizagem conceitual. ${ }^{9}$ Todavia, não é consensual a ideia de utilizar experimentos para introduzir conceitos. Wellington, ${ }^{4}$ por exemplo, desacredita na experimentação como forma de "ensinar a teoria", visto que os alunos teriam dificuldades para explicar o fenômeno observado sem terem se apropriado do conhecimento teórico. Tal perspectiva de introduzir conhecimentos teóricos por meio da experimentação, segundo o autor, pode aludir à aprendizagem por descoberta. Essa defesa não significa, em absoluto, negar a utilização das atividades experimentais no momento inicial do ensino de um conteúdo teórico. Shiland, ${ }^{10}$ nessa direção, sinaliza a possibilidade de explorar experimentos para favorecer a explicitação do conhecimento discente sobre o assunto a ser ensinado.

$\mathrm{O}$ ensino e a aprendizagem de procedimentos foram do mesmo modo ressaltados. Um tipo de procedimento apontado como conteúdo a ser aprendido nas atividades experimentais foi a observação:

Neste tipo de atividade, pode-se observar que experimentos demonstrativos despertam as habilidades de observação $e$ envolvem os alunos, chamando a atenção pela sensibilidade. Cabe ao professor mediar a assimilação do conhecimento vinculado a cada experimento ${ }^{11}$ ( $p$. 178).

Aprender a observar é um objetivo bastante antigo atribuído aos experimentos. Zanetic, ${ }^{12}$ há mais de 30 anos, já tinha identificado a valorização de tal objetivo entre docentes de Física na educação superior. Isso pode estar associado, às vezes, ao entendimento empirista de que a construção do conhecimento tem como gênese a observação neutra. Contrariamente, compreende-se que ensinar os alunos a observar implica ensiná-los a utilizar os conhecimentos teóricos para tal, isto é, a experimentação não ocorre no "vácuo teórico". ${ }^{4}$

Os conteúdos atitudinais, por sua vez, aparecem de forma mais tácita que os conceituais e procedimentais nas propostas analisadas. Exemplos de conteúdos atitudinais são apresentados abaixo:

Através do desenvolvimento do processo de extração do óleo de soja, o aluno pode discutir técnicas de laboratório [...], conceitos químicos básicos [...], precauções e segurança em laboratório e na indústria [...], aspectos econômicos do processo químico industrial e cuidados que devem ser tomados na preservação do meio ambiente ${ }^{13}$ (p. 765).

Os cuidados associados à segurança e ao "meio ambiente" na condução dos processos químicos são exemplos de atitudes a serem ensinadas durante as atividades experimentais. Aprender a respeitar o "meio ambiente" é um conteúdo a ser ensinado nas diferentes áreas da Química e por meio de atividades para além da experimentação. Acrescenta-se que é pouco adequado elaborar atividades para abordar somente uma determinada atitude. ${ }^{7} \mathrm{O}$ fragmento também indica que os conceitos, procedimentos e atitudes são conteúdos que se relacionam e a distinção entre eles é de ordem analítica. Freire, ${ }^{14}$ ao se referir ao ensino de Biologia - e suas considerações também são válidas para o ensino de Química - , destaca que o fato de se ensinar Biologia não significa que o desenvolvimento de tal processo deva ocorrer fora da trama histórico-social, cultural e política, pelo contrário. Em outras palavras, em uma perspectiva progressista de educação, o ensino de Química não se restringe ao ensino de conteúdos puramente conceituais.

Enfim, as propostas analisadas sugerem a experimentação como um modo de ensinar conceitos, procedimentos e atitudes. Uma ideia presente em propostas é que os experimentos poderiam se constituir em uma maneira de introduzir conceitos e nisso pode estar implícita uma crença na visão empirista que, ao mesmo tempo, pode permear outros objetivos comumente atribuídos às atividades experimentais. $\mathrm{O}$ ensino de atitudes apareceu de forma mais implícita, embora entendamos que um docente não pode decidir se seus alunos irão aprender ou não atitudes, mas quais atitudes podem aprender, pois na prática pedagógica há exemplos de conteúdos atitudinais mesmo que o professor não os identifique. Compreendemos que a análise exposta reforça uma premissa da perspectiva progressista de educação aqui defendida, isto é, de que a abordagem de conteúdos conceituais não é inconciliável com a formação moral dos educandos. ${ }^{15} \mathrm{E}$ uma visão que entende os experimentos como modo de ensinar somente conceitos e procedimentos precisa ser problematizada nos processos de formação docente, em geral. Interpretamos que a ênfase explícita nos conteúdos conceituais e procedimentais nas propostas de experimento pode estar associada à forma como a experimentação tem sido aprendida pelos docentes de Química da educação superior, ou seja, minimamente problematizada.

\section{CONTEÚDOS NA EXPERIMENTAÇÃO: A IMPORTÂNCIA DO QUE SE APRENDE}

O discurso sobre os conteúdos abordados nas atividades experimentais é acompanhado de considerações acerca da importância de aprendê-los. Em certa medida, isso imprime determinadas características aos experimentos, como a possibilidade de exemplificar conceitos:

[...] visando à elaboração de experimentos para uma disciplina experimental avançada de química orgânica [...] pensou-se em projetos de sintese [...] com as seguintes características: compatibilidade com o tempo disponível, produtos de fácil purificação e caracterização [...] e, principalmente, experimentos que permitissem aos alunos a sedimentação de conceitos básicos, com exemplos envolvendo aspectos de suas vidas cotidianas ${ }^{16}$ (p. 284).

A utilização das atividades experimentais para exemplificar o conteúdo em situações cotidianas do aluno é uma característica do discurso a respeito da experimentação, notadamente para a educação básica. ${ }^{17} \mathrm{~A}$ ideia de ensino de Química do cotidiano tem sido criticada, especialmente no âmbito do ensino médio, devido ao seu caráter "conteudista" disfarçado com aspectos do dia a dia dos estudantes. ${ }^{18}$ O conceito de contextualização, mais complexo do que a ideia de ensino de Química do cotidiano, perpassou igualmente as propostas analisadas:

A contextualização do ensino é fundamental para que a aprendizagem seja efetiva isto fica bem claro na essência dos Parâmetros Curriculares Nacionais - PCN's [...] Os experimentos realizados são simples, têm baixo custo e envolvem uso de poucos reagentes e materiais. Conceitos químicos importantes podem ser abordados de maneira contextualizada com as atividades experimentais descritas, sendo que conforme o grau de dificuldade e sofisticação podem ser adaptadas com o nível de ensino a que se destinem. Dada a simplicidade da proposta, as aplicações didáticas podem ser realizadas sem a necessidade de infra-estrutura laboratorial para aulas práticas ${ }^{19}$ (p. 685).

Os autores evocam o discurso oficial de inovação curricular da educação básica para apoiar o conceito de contextualização. Esse conceito é caracterizado pela sua polissemia na discussão educacio- 
nal, e a sua "incorporação" é interpretada positivamente no discurso sobre a experimentação. ${ }^{20}$ Uma possibilidade de favorecer um ensino contextualizado pode ser a busca por uma articulação com os referenciais ligados ao "enfoque" Ciência, Tecnologia e Sociedade (CTS) no ensino:

Estamos convencidos de que a abordagem CTS, usando problemas de Química relacionados com situações reais e do cotidiano, salienta a relevância dos conceitos básicos de química, motivando e despertando maior interesse do aluno no processo de aprendizagem ${ }^{13}$ (p. 767).

O fomento à realização de atividades experimentais com "enfoque" CTS já tem sido apresentado no ensino de Ciências. ${ }^{21}$ Entre as contribuições apontadas na literatura acerca da inserção da abordagem CTS no ensino é possível mencionar o combate a uma visão linear de desenvolvimento científico e tecnológico, segundo a qual esse desenvolvimento implicaria obrigatoriamente em mais riquezas e bem-estar social, assim como à suposta neutralidade da Ciência e da Tecnologia. Embora o ensino de Ciências fundamentado no "enfoque" CTS possa ser caracterizado por diferentes objetivos, como aqueles sinalizados implicitamente no fragmento acima, cuja finalidade é motivacional, entendemos que esse "enfoque" pode colaborar para a construção de conhecimentos científicos e de valores importantes na tomada de decisões relativas a problemas relacionados à Ciência e à Tecnologia.

Na visão dos autores citados, os experimentos podem ser um meio de favorecer a exemplificação de aspectos do dia a dia dos estudantes e que estão relacionados aos conteúdos. Os experimentos "contextualizados" e orientados por uma abordagem CTS se aproximam de uma visão mais complexa relativa às atividades experimentais. Neste sentido, a intenção de abordar uma realidade que transcenda o meio "escolar" por meio de experimentos pode ser apoiada por articulações recentes entre o referencial freireano e aqueles relacionados ao "enfoque" CTS. ${ }^{22}$ Essa perspectiva chama a atenção para o fato de que a leitura crítica da realidade, reivindicada por Freire, ${ }^{23}$ está associada a uma compreensão igualmente crítica das interações entre Ciência, Tecnologia e Sociedade. De acordo com Freire, ${ }^{24}$ o desvelamento da realidade ocorre na superação da pura "doxa" - mera opinião ingênua - pelo logos da realidade, ou seja, por meio da tomada de consciência da realidade via problematização, e que, portanto, visa a uma ação transformadora, a qual independeria da apropriação de conhecimentos relacionados unicamente à Ciência e à Tecnologia. Cumpre notar ainda que a presença do discurso de inovação curricular para a educação básica em textos analisados parece ser uma intenção de estender aquilo que é realizado na educação superior para esse nível educacional.

\section{CONTEÚDOS NA EXPERIMENTAÇÃO: PARA ALÉM DA DISCIPLINARIDADE}

Parte dos autores enfatizou, de forma explícita, a necessidade de a experimentação ser desenvolvida em uma perspectiva que transcenda a dimensão puramente disciplinar. Neste sentido, o discurso sobre a interdisciplinaridade permeou determinados textos:

As atividades experimentais deste trabalho podem ser empregadas didaticamente para favorecer a articulação entre teoria e prática no ensino superior [...] e como um tema interdisciplinar no ensino médio, atendendo as recomendações dos PCN's. A interdisciplinaridade deste experimento consiste desde os procedimentos da química analítica, orgânica e físico-química, até os conceitos de biologia (classificação botânica) e geografia (tipo de clima e solo para o cultivo destas espécies) $[\ldots]^{19}$ (p. 687).

Mais uma vez, a voz das orientações curriculares oficiais aparece como um modo de apoiar a proposta de atividade experimental dos autores. A menção aos Parâmetros Curriculares Nacionais (PCN) parece ser uma maneira de incentivar a realização do experimento no ensino médio. A descrição acima sugere que o assunto abordado no experimento pode ser compreendido melhor quando estudado à luz dos conhecimentos de diferentes áreas. Essa é uma característica positiva do assunto, mas também é importante discutir o conceito de interdisciplinaridade diante da quantidade de significados que o termo pode assumir na literatura. Apesar de o assunto estar fortemente entremeado por conceitos de Biologia e Geografia, não é papel do professor de Química ensiná-los, sobretudo porque não possui a qualificação que outro profissional tem para ensinar um conceito de sua área. Nisso está implícito o respeito a determinados níveis de fragmentação do conhecimento, sem negar a necessidade de totalização, como prevê uma perspectiva progressista de educação. ${ }^{25}$

$\mathrm{O}$ conceito de multidisciplinaridade também emergiu em propostas analisadas:

Cada um dos experimentos elaborados, neste trabalho, visa à introdução de conteúdos tradicionais aliados a conteúdos não convencionais, mostrando a multidisciplinaridade presente na química orgânica atual $[\ldots]^{26}$ (p. 1112).

A multidisciplinaridade mencionada parece se referir a assuntos que necessitam de distintas áreas para tratar o fenômeno estudado. Destaca-se que a multidisciplinaridade não provoca, obrigatoriamente, a integração teórica ou metodológica de distintas áreas de conhecimento. ${ }^{27}$

Portanto, parte das propostas analisadas procura se inserir em uma perspectiva que não se encerra em um discurso excessivamente disciplinar e fragmentado. Todavia, é importante reiterar que não é papel exclusivo da experimentação promover um ensino menos fragmentado. Os argumentos explorados nessa categoria são indicativos da necessidade, já mencionada anteriormente, ${ }^{5}$ de que a presença da problematização na abordagem dos conteúdos durante a atividade experimental é algo importante no próprio processo de problematização de tais atividades na educação superior em Química.

\section{A RELAÇÃO ENTRE TEORIA E EXPERIMENTAÇÃO}

Os artigos foram permeados por compreensões diferentes sobre a relação entre teoria e prática/experimentação. Houve casos em que se criticou a imaginável dicotomia entre teoria e prática/experimentação:

Na maioria dos cursos de química das universidades brasileiras, o ensino experimental tem uma presença apenas marginal e, muitas vezes, limita-se a demonstrações ou experimentos em grupo. [...] Pelo menos em Química Orgânica, a maior responsabilidade deve ser creditada, ao nosso ver, à ideia muito generalizada de que um curso experimental visa principalmente a um treinamento de procedimentos manuais, tradicionalmente relegados a técnicos e laboratoristas, e pouco acrescenta às atividades mais "nobres", ou seja, o estudo teórico de estruturas e mecanismos. Contribui muito para essa imagem deformada a apresentação das experiências como simples "receitas de cozinha" que devem ser seguidas à risca e cujo resultado já conhecido antecipadamente de maneira que as práticas dispensam o raciocínio próprio e a aplicação de conhecimentos teóricos ${ }^{28}$ (p. 605). 
Admitir os experimentos como colaboradores da aprendizagem de procedimentos manipulativos não significa encerrá-los em tal contribuição, pois estes podem favorecer também a apropriação de conhecimentos teóricos. Sabe-se, no entanto, que nas atividades experimentais os discentes destinam muito tempo para a manipulação de equipamentos em detrimento da aprendizagem conceitual, ${ }^{29}$ que também pode ser empobrecida pelas denominadas demonstrações. As demonstrações podem possuir a função de "comprovar a teoria na prática". Experimentos cujo único objetivo é comprovar um conhecimento teórico se aproximam de uma perspectiva bancária de educação, criticada pelo viés progressista aqui explorado. Com isso, não se opõe de forma absoluta às denominadas aulas expositivas, pois nem toda aula com essa característica desconsidera a relação dialógica do ato educativo. ${ }^{14}$ Cabe ressaltar ainda que o termo demonstração pode assumir outro sentido, a saber: experimentos nos quais o professor é o manipulador dos equipamentos. ${ }^{17}$ Do mesmo modo, o termo verificação pode ser caracterizado por uma polissemia e, portanto, não necessariamente remete à ideia de verificacionismo.

A compreensão da relação entre teoria e prática aparece também no discurso sobre o papel da observação nos experimentos:

A questão 2 do relatório, solicitando a descrição das observações dos testes de condutividade do líquido, antes e após a passagem pelas resinas, visava verificar se os estudantes são capazes de separar a mera descrição dos fatos experimentais e a interpretação dos mesmos. As respostas indicaram que $55 \%$ dos alunos do ensino superior fazem esta distinção $[\ldots]^{30}($ p. 963).

Para certificar que o borbulhamento observado é devido à formação do alceno e não à expansão do ar do interior da aparelhagem, deixa-se, inicialmente, que o borbulhamento se dê num tubo de ensaio contendo 2-3 mL de solução $1 \%$ de $\mathrm{KMnO}_{4}[\ldots]$ Tão logo se observe a mudança da coloração de violeta para castanha, troca-se o tubo de ensaio pelo frasco de reação ${ }^{31}$ (p. 426).

No primeiro fragmento está implícita a ideia de que é possível dissociar a observação da interpretação. A epistemologia contemporânea argumenta o contrário, isto é, toda a observação é orientada por um conhecimento prévio. Essa compreensão parece estar tácita no segundo fragmento ao considerar a observação como pautada em uma teoria. Nisso estaria subentendida a necessidade de aprender os conhecimentos científicos para observar cientificamente. Mas a experimentação também é entendida como forma de introduzir teorias: "Com este dado pode-se estender o experimento e fazer uma introdução à teoria do campo cristalino" 32 (p. 725). As teorias como oriundas apenas dos dados obtidos através da observação e experimentação são um entendimento de senso comum que pode ter como gênese o empirismo ingênuo, para o qual a Ciência começa na observação neutra e realizada em grande número e em ampla variedade de circunstâncias.

Compreender as atividades experimentais como forma de demonstrar/comprovar/verificar a teoria ou introduzi-la é um posicionamento que precisa ser problematizado, assim como a valorização da observação neutra. Acreditar nos experimentos como meio de comprovar uma teoria ou introduzi-la são posicionamentos, até segunda ordem, opostos, pois um se aproxima mais do empirismo, cujo prisma da construção do conhecimento tem na observação sensível - observação neutra - a gênese desse conhecimento. Enquanto isso, a ideia de comprovação de um conhecimento se fundamenta na possibilidade de comprovar o já produzido. Tal cenário sugere a necessidade de investigar como essa "contradição" aparece entre os docentes de Química.

\section{MOTIVAÇÃO: OBJETIVO DA EXPERIMENTAÇÃO?}

A compreensão arraigada entre os professores de que as atividades experimentais são um meio para motivar os alunos apareceu sob diferentes enfoques. Entre esses enfoques, está aquele que acredita na experimentação, por si só, como motivadora:

É consenso que a experimentação desperta interesse entre os alunos, independente do nível de escolarização. Os experimentos demonstrativos ajudam a enfocar a atenção do estudante nos comportamentos e propriedades de substâncias químicas e auxiliam, também, a aumentar o conhecimento e a consciência do estudante de química ${ }^{11}$ (p. 173).

Não é consenso a ideia de que os experimentos motivam de forma incondicional. ${ }^{17,25}$ Pelo contrário, às vezes os alunos têm aversão à realização de experimentos. ${ }^{25} \mathrm{~A}$ motivação em sala de aula é um fenômeno complexo para ter a sua discussão encerrada em torno da experimentação. Por exemplo, a avaliação é um dos aspectos que podem estar relacionados com a motivação discente. ${ }^{33} \mathrm{~A}$ psicologia contemporânea também destaca que é muito difícil identificar a influência de fatores internos ou externos sobre o comportamento dos estudantes. ${ }^{34}$ Outro enfoque, menos expressivo, é o da "motivação" como decorrente da aprendizagem proporcionada pelo experimento:

[...] os autores do artigo notaram um grande entusiasmo dos alunos durante a execução do experimento, especialmente pela aprendizagem de novos conceitos e também pela sua ligação com outros fatos da química do estado sólido ${ }^{35}$ (p. 499).

A passagem acima parece estar em harmonia com o posicionamento de Tapia, ${ }^{33}$ ou seja, às vezes não é a desmotivação em si a causadora da pouca aprendizagem dos alunos, mas o inverso, a desmotivação como consequência da mínima aprendizagem. Isso sugere que talvez o professor tenha como foco principal da sua ação a aprendizagem e não a motivação, que, por sua vez, seria uma decorrência da aprendizagem. Porém, a preocupação docente com a aprendizagem não tem como resultado, obrigatoriamente, a motivação do aluno, pois, como argumentado anteriormente, essa motivação é um fenômeno complexo.

Enfim, o entendimento da experimentação como promotora incondicional da motivação precisa ser mais problematizado, visto que parece ser constituinte de um senso comum pedagógico.

\section{O ERRO E SUAS IMPLICAÇÕES NA EXPERIMENTAÇÃO}

O erro apareceu com significados variados em propostas de experimento. $\mathrm{O}$ mais expressivo foi aquele com sentido estatístico:

[...] não há necessidade de se empregarem balanças analíticas para a determinação da massa da gota [...] é possível utilizar balanças semi-analíticas, observando-se que um número maior de gotas deve ser coletado, a fim de minimizar o erro experimental advindo deste instrumento ${ }^{36}$ (p. 495).

A noção matemática de erro é constituinte do discurso acerca da experimentação na Química e no seu ensino. As considerações acima parecem se aproximar do posicionamento de Bachelard ${ }^{37}$ quando afirma ser necessário refletir para medir. Essa reflexão é um modo de não entender as atividades experimentais como a execução de uma "receita de bolo". O cálculo do erro tem sido um dos objetivos atribuídos à experimentação por docentes de Física na educação superior, especialmente com a intenção de ajustar o fenômeno à teoria. ${ }^{38}$ 
O erro no experimento ainda pode atingir outros significados e que apareceram de forma menos expressiva, como o que segue abaixo:

\section{[...] foi observado que no caso do vinagre de vinho tinto, a viragem dos indicadores alternativos não é clara, passando de vermelho para castanho no ponto final. Como conse- quência, observam-se erros relativos elevados em relação à fenolftaleína. Esta interferência deve ser causada pela presença de antocianinas e outros compostos da uva [...] não funcionando como indicadores de acordo com testes realizados $[\ldots]^{39}$ (p. 410-411).}

A compreensão de erro implícita acima parece estar em consonância com a epistemologia bachelardiana, ${ }^{37}$ pois não se trata de um erro oriundo da distração ou "falta de informação". É um erro do qual o sujeito inicialmente não tem clareza de como se desvencilhar. Os experimentos com esse "tipo de erro" podem contribuir sobremaneira para a aprendizagem, porque, como ressalta Bachelard, ${ }^{37}$ "a primeira experiência exigente é a experiência que falha" (p. 126). Ou seja, tentar entender o que não se consegue explicar, ou o imprevisto, é um aspecto importante na experimentação.

Portanto, o discurso relativo ao erro pode ser um aspecto positivo se for interpretado como ponto de partida para enriquecer o conhecimento discente. Tanto o erro cometido por falta de informação ou distração, e que pode ser identificado posteriormente, como aquele que o sujeito não tem lucidez para identificar e do qual não consegue se separar, podem ser objetos de diálogo. Isso significa que a noção de erro pode ser um dos aspectos problematizados nos experimentos na educação superior.

\section{A MODO DE CONCLUSÃO}

Do exposto na análise se destaca o papel dos conteúdos conceituais, procedimentais e atitudinais. Ressalta-se, por exemplo, a importância destinada à observação e a sua relação com as atividades experimentais. Outra característica acentuada nas propostas de experimento entre os textos analisados foi a de exemplificar os conceitos com situações "cotidianas". Conforme discutido, esse aspecto já foi evidenciado em estudos anteriores sobre a experimentação no ensino médio, algo que se diferencia das noções mais contemporâneas em torno da contextualização do ensino, que esteve também presente em propostas analisadas. As compreensões sobre a relação entre teoria e prática/experimentação ainda mostram, em certas ocasiões, influências de uma perspectiva mais empirista-indutivista. A crença bastante antiga de que as atividades experimentais são motivadoras se fez presente, inclusive em sugestões de experimentos mais atuais. A função que o erro pode ter na experimentação permeou ainda as propostas de atividades experimentais.

Visões como aquelas que se mostram em sintonia com uma perspectiva mais empirista-indutivista e com a ideia de que a experimentação é incondicionalmente motivadora podem constituir aquilo que Freire ${ }^{23}$ denomina de consciência real efetiva ou consciência ingênua, que precisa ser superada — com o apoio de uma prática educativa dialógica e problematizadora - por uma consciência máxima possível $^{23}$ ou consciência crítica. Um exemplo de entendimento que constitui uma consciência máxima possível é aquele que compreende as atividades experimentais como um artefato que pode favorecer, além das aprendizagens conceituais e procedimentais, a apropriação de conteúdos atitudinais.

As categorias aqui discutidas, somadas às precedentes, ${ }^{5}$ configuram um quadro de possibilidades teóricas e metodológicas à experimentação, podendo subsidiar não somente o planejamento de experimentos de docentes da educação superior em Química como também processos formativos destinados a professores de Química. Se as propostas analisadas dão indicativos de avanços nos discursos em torno da experimentação, quando comparados àqueles que entremeavam os projetos de ensino de Ciências oriundos dos Estados Unidos e Inglaterra (Chemical Education Material Study etc.) e que muita influência tiveram no cenário educacional brasileiro,${ }^{40}$ também são indicativos da necessidade de problematizar os discursos de professores de Química da educação superior sobre as atividades experimentais no ensino de Química.

Considera-se que as discussões realizadas aqui endossam as argumentações promovidas anteriormente, ${ }^{5}$ de modo a reforçar a importância da problematização da experimentação - e de outros conteúdos relativos à docência em Química — no desenvolvimento profissional dos professores de Química da educação superior. Merece ser ressaltado que mais uma vez o discurso educacional voltado para o ensino de Química na educação básica esteve presente em artigos com propostas de experimento. A disseminação de propostas de experimentos em veículos como a Química Nova, em harmonia com as contribuições contemporâneas da pesquisa em ensino de Ciências, pode colaborar no processo de problematização das atividades experimentais na educação superior em Química, de modo que se possa enfrentar de forma mais efetiva a crença de que a experimentação é promotora incondicional da aprendizagem.

\section{REFERÊNCIAS}

1. Galiazzi, M. C.; Rocha, J. M. B.; Schmitz, L. C.; Souza, M. L.; Giesta, S.; Gonçalves, F. P.; Ciência \& Educação 2001, 7, 249.

2. Schnetzler, R. P.; Quim. Nova 2002, 25 Suplemento 1, 14.

3. Francisco, C. A.; Queiroz, S. L.; Quim. Nova 2008, 31, 2100.

4. Wellington, J. Em Practical Work in school science: which way now?; Wellington, J., ed.; Routledge: London, 1998, cap. 1.

5. Gonçalves, F. P.; Marques, C. A.; Quim. Nova 2011, 34, 899.

6. Moraes, R.; Galiazzi, M. C.; Análise Textual Discursiva, Editora Unijuí: Ijuí, 2007.

7. Pozo, J. I. Em Psicologia da aprendizagem no ensino médio; Coll, C., ed.; Artmed: Porto Alegre, 2003, cap. 2.

8. Leite, O. D.; Fatibello-Filho, O.; Rocha, F. R. P.; Quim. Nova 2004, 27, 337.

9. Lopes, J. B.; Enseñanza de las Ciencias 2002, 20, 115.

10. Shiland, T. W.; J. Chem. Educ. 1999, 76, 107.

11. Arroio, A.; Honório, K. M.; Weber, K. C.; Homem-de-Mello, P.; Gambardella, M. P.; Silva, A. B. F.; Quim. Nova 2006, 29, 173.

12. Zanetic, J.; Dissertation, University of London, England, 1974.

13. Vianna, J. F.; Pires, D. X.; Viana, L. H.; Quim. Nova 1999, 22, 765.

14. Freire, P.; Pedagogia da Esperança: um reencontro com a pedagogia do oprimido, Paz e Terra: Rio de Janeiro, 1992.

15. Freire, P.; Pedagogia da Autonomia: saberes necessários à prática educativa, 30ª ed., Paz e Terra: São Paulo, 1996.

16. Baptistella, L. H. B.; Giacomini, R. A.; Imamura, P. M.; Quim. Nova 2003, 26, 284.

17. Gonçalves, F. P.; Marques, C. A.; Investigações em Ensino de Ciências 2006, 11, 219.

18. Santos, W. L. P.; Mortimer, E. F.; Ensaio-Pesquisa em Educação em Ciências 2000, 2, 133.

19. Terci, D. B. L.; Rossi, A. V.; Quim. Nova 2002, 25, 684.

20. Gonçalves, F. P.; Galiazzi, M. C. Em Educação em Ciências: produção de currículo e formação de professores; Moraes, R.; Mancuso, R., eds.; UNIJUÍ: Ijuí, 2004, cap. 10.

21. Carrascosa, J.; Pérez, D. G.; Vilches, A.; Valdés, P.; Caderno Brasileiro de Ensino de Física 2006, 23, 157.

22. Muenchen, C.; Auler, D.; Revista Brasileira de Pesquisa em Educação em Ciências 2007, 7, 227. 
23. Freire, P.; Pedagogia do Oprimido, $40^{\mathrm{a}}$ ed., Paz e Terra: Rio de Janeiro, 2005.

24. Freire, P.; Extensão ou comunicação?, Paz e Terra: Rio de Janeiro, 1977.

25. Delizoicov, D.; Zanetic, J. Em Ousadia no diálogo: interdisciplinaridade na escola pública; Pontuschka, N., ed.; Loyola: São Paulo, 1993, cap. 1.

26. Navarro, M.; Sena, V. L. M.; Srivastava, R. M.; Navarro, D. M. A. F.; Quim. Nova 2005, 28, 1111.

27. Carvalho, I. C. M.; Educação Ambiental: a formação do sujeito ecológico, Cortez: São Paulo, 2004

28. Bieber, L. W.; Quim. Nova 1999, 22, 605.

29. Hodson, D.; Enseñanza de las Ciencias 1994, 12, 299.

30. Osório, V. K. L.; Kuya, M. K.; Maia, A. S.; Oliveira, W.; Quim. Nova 2003, 26, 960 .

31. Cunha, S.; Lião, L. M.; Bonfim, R. R.; Bastos, R. M.; Monteiro, A. P. M.; Alencar, K. S.; Quim. Nova 2003, 26, 425.

32. Pissetti, F. L.; Nonô, R. S.; Gushiken, Y.; Dias, G. H. M.; Quim. Nova 2007, 30, 723 .
33. Tapia, J. A. Em ref. 7, cap. 4.

34. Guimarães, S. E. R. Em A motivação do aluno: contribuições da psicologia contemporânea; Boruchovitch, E.; Bzuneck, J. A., eds.; Vozes: Petrópolis, 2001, cap. 2.

35. Zarbin, A. J. G.; Davanzo, C. U.; Quim. Nova 1995, 18, 494

36. Behring, J. L.; Lucas, M.; Machado, C.; Barcellos, I. O.; Quim. Nova 2004, 27, 492

37. Bachelard, G.; A formação do espírito científico: contribuição para uma psicanálise do conhecimento, Contraponto: Rio de Janeiro, 1996.

38. Antúnez, G. C.; Pérez, S. M.; Petrucci, D.; Revista Brasileira de Pesquisa em Educação em Ciências 2008, 8, 101.

39. Soares, M. H. F. B.; Cavalheiro, E. T. G.; Antunes, P. A.; Quim. Nova 2001, 24, 411 .

40. Villani, A.; Pacca, J. L. A.; Science \& Education: contributions from History, Philosophy and Sociology of Science and Mathematics 2009, 18,125 . 